\title{
A Comprehensive Measurement of Progress toward Local SDGs with Geospatial Information: Methodology and Lessons Learned
}

\author{
Jun Chen ${ }^{1, *}$, Shu Peng ${ }^{1}$, Hao Chen ${ }^{2}$, Xuesheng Zhao ${ }^{3} \oplus$, Yuejing Ge ${ }^{4}$ and Zhilin $\mathrm{Li}^{5}$ \\ 1 National Geomatics Center of China, Beijing 100830, China; pengshu@ngcc.cn \\ 2 National-Local Joint Engineering Laboratory of Geo-Spatial Information Technology, Hunan University of \\ Science and Technology, Xiangtan 411201, China; chenhao@hnust.edu.cn \\ 3 College of Geoscience and Surveying Engineering, China University of Mining \& Technology (Beijing), \\ Beijing 100083, China; zxs@cumtb.edu.cn \\ 4 Faculty of Geographical Sciences, Beijing Normal University, Beijing 100875, China; geyj@bnu.edu.cn \\ 5 Faculty of Geosciences and Environmental Engineering \& State-Province Joint Engineering Laboratory of \\ Spatial Information Technology for High-speed Railway Safety, Southwest Jiaotong University, \\ Chengdu 611756, China; Dean.ge@swjtu.edu.cn \\ * Correspondence: chenjun@ngcc.cn
}

Received: 13 July 2020; Accepted: 29 August 2020; Published: 1 September 2020

\begin{abstract}
The UN's 2030 Agenda defined 17 Sustainable Development Goals (SDGs). In order to ensure the implementation of this global agenda, the UN proposed a systematic follow-up and review through indicator-based tracking and reporting of the progress with statistical and geospatial information toward SDGs at national, regional, and global levels. This has posed many technical and institutional challenges. Although international communities have devoted great attention to this hot topic, most of their work has focused on the conceptual design and preliminary testing. There are very few good practices for a comprehensive measurement and assessment of progress toward SDGs with the integration of statistical and geospatial information at national or local levels. This paper presents the methodology and results of a pioneer project which measured the progress toward SDGs at a local level in China (i.e., Deqing County) by integrating statistical and geospatial information. In this study, a number of technical/institutional issues have been tackled, such as the adoption of appropriate indicators at a local level, availability and acquisition of reliable data sets, and spatiotemporal analysis with a geographical perspective, interaction between SDGs and cross-sector coordination. The major conclusions are (a) the comprehensive progress toward SDGs in Deqing can be most appropriately measured and assessed by integrating geospatial and statistical information; (b) Deqing has made significant economic and social advances while maintaining a good ecological environment over the past few years. The results were released at the first United Nations World Geospatial Information Congress as a good practice and a live example to stimulate discussions.
\end{abstract}

Keywords: 2030 Agenda; Sustainable Development Goals (SDGs); geospatial information; indicators; measurement

\section{Introduction}

The United Nations 2030 Agenda for Sustainable Development (hereinafter referred to as the 2030 Agenda) set up 17 Sustainable Development Goals (SDGs) and 169 targets, aiming to end poverty and promote prosperity and people's well-being while protecting the environment by 2030 at national, regional, and global levels [1]. In order to ensure successful implementation of this global agenda, the United Nations called upon a systematic follow-up and review of the progress toward SDGs [2,3] in 
accordance with a SDGs Global Indicator Framework (hereafter called SGIF) [4], which was developed by the Inter-Agency and Expert Group on SDG Indicators (IAEG-SDGs) [5]. The SGIF consists of more than 230 indicators, with at least one indicator for each of the 169 targets. The measurement of these indicators and the progresses toward SDGs places significant demands on timely, reliable, and disaggregated data with a number of specific requirements, including geospatial dimensions [6-9].

Efforts have been devoted to the measurement and monitoring the progress toward SDGs during the last few years. At global and regional levels, the Sustainable Development Solutions Network (SDSN) used statistical data from the World Bank database to assess SDGs baselines for 149 countries with reference to the SDG index and dashboards [10,11]. The United Nations Economic and Social Commission for Western Asia (UN-ESCWA) measured the progress toward SDGs in 22 countries of the Arab region with the help of 20 years of statistical data [12]. Researchers from South Africa used the statistical databases of World Bank and the UN Food and Agriculture Organization (FAO) to assess the agricultural sustainability in Southern Africa [13]. At a national level, progress and priorities for the SDGs were also assessed in Australia and China [14,15]. At a subnational level, such studies are not rare $[15,16]$. However, there is a common problem associated with these studies, i.e., only making use of statistical data but not of geospatial information. This leads to difficulties in describing geographic patterns, revealing regional differences, and exploring spatiotemporal effects of SDGs practices, because many SDGs, targets, and indicators have a geographic nature.

It is therefore imperative to harness geospatial information in measuring and monitoring the progress toward SDGs [17-19]. In 2017, the Working Group on Geospatial Information of the IAEG-SDGs was established (named as IAEG-SDGs: WGGI) to explore the role of geospatial information and promote its utilization in SDGs monitoring [20]. They identified more than 20 SDGs indicators which could be derived directly or indirectly with geospatial information [21,22]. The Group on Earth Observations (GEO) launched an initiative "Earth Observations for Sustainable Development (EO4SDG)" (http://eo4sdg.org/) and organized a series of workshops and capacity-building activities [23]. In 2019, the Chinese Academy of Sciences held a press conference in Beijing on the report of Earth Big Data Supporting Sustainable Development Goals. This report cites 12 typical cases centered on 11 SDG indicators of five selected SDGs (SDG2, 6, 11, 14, 15) which could be derived directly or in-directly with geospatial information [24]. Nowadays, there is a growing number of publications regarding the utilization of geospatial information and earth observation in SDGs measurement and monitoring [23-26]. However, most of them have discussed only a single or a few indicators [27-29], or a single goal or target [30-33]. Thus, these studies are not capable of providing an overall picture regarding the achievement of sustainability goals.

The 2030 SDGs was defined as an "indivisible whole" embracing three pillars, i.e., economic prosperity, social inclusion, and environmental protection [34,35]. In order to provide an overall picture regarding the distance from achieving the 2030 SDGs, a holistic performance evaluation of all goals and targets should be realized by a comprehensive measurement and with an integrated utilization of geospatial and statistical information $[8,36]$. To address this challenge, a pilot study was conducted by the authors in Deqing county of the Zhejiang Province, China [37]. It aimed to answer two basic questions: (1) How can the overall progress toward the SDGs at a local level be measured in alignment with the United Nations SGIF through integration of geospatial and statistical information? (2) How far is the county from achieving 2030 SDGs? To complete such a project, a number of technical problems needed to be solved, including the adoption of appropriate sets of indicators covering all the three SDG pillars, the preparation and provision of reliable and ready-to-use geospatial data, the calculation and analysis of SDGs indicators and goals (and targets) with a geospatial lens, and the overall evaluation of the sustainability performance.

This paper presents the overall methodology and major outputs of this pilot research project. Section 2 summarizes the overall methodology, which is characterized as SGIF-aligned, data-driven, and evidence-supported. Section 3 describes how a set of 102 local indicators were selected through a localization analysis of SGIF and how they were calculated with a geospatial lens. An evidence-based, 
three-level assessment and its results are provided in Section 4. Further research issues are discussed in Section 5.

\section{Methodology}

A comprehensive SDGs progress measurement in a local context depends critically on how to adopt/adapt adequate indicators in alignment with the SGIF and covering its major sustainable development aspects, whether reliable geospatial and statistical data are available, how to measure the indicators in support of geospatial information, and what quantitative and qualitative evidences can be used to assess the progress [38]. The methodology is summarized and illustrated by Figure 1, which is characterized as indicator-based, data-driven, and evidence-supported.

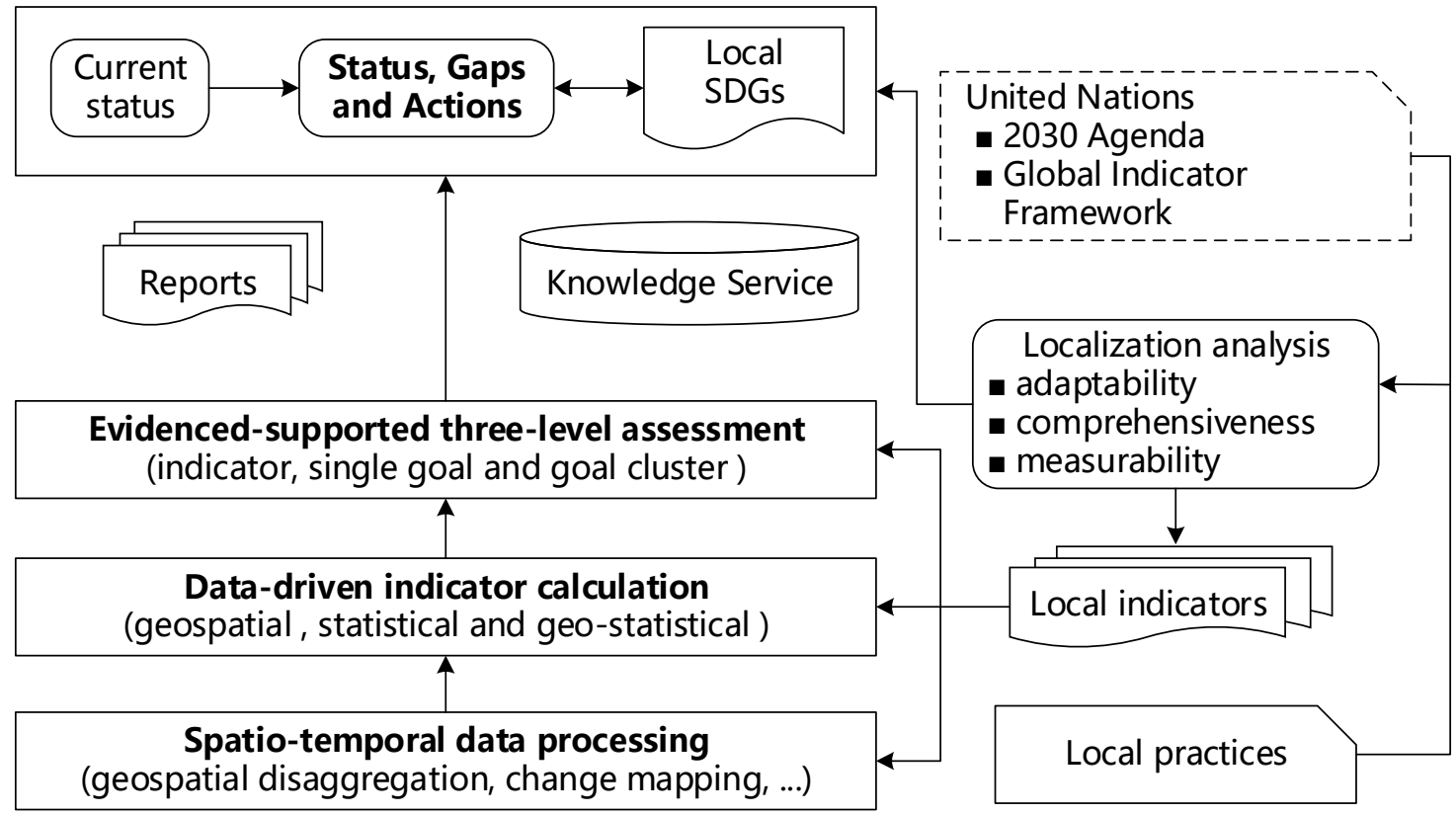

Figure 1. Methodology for a comprehensive measurement of progress toward Sustainable Development Goals (SDGs).

\section{(1) SGIF-Aligned Indicator Adoption}

The United Nations SGIF was taken as a starting point of the adoption of adequate indicators. The alignment with SGIF enables an international comparison [12]. Since the SGIF was designed originally from global perspective, it may not meet all the requirements of a local SDGs study. In order to tailor it to local circumstance, three criteria were proposed for performing a localization analysis, i.e.,

- Adaptability: Referring to the analysis of whether each indicator of the Global Indicator Framework has a practical significance for the local context or adapts to the local development priorities;

- Comprehensiveness: Meaning that the selected indictors should cover the major aspects of local SDGs;

- Measurability: Used for determining whether each selected indicator can be quantified with reliable geospatial and statistical data.

After such an analysis, it was found that many indicators could be adopted directly from the SGIF, but some others might be subject to necessary extension, revision, or substitution.

(2) Spatiotemporal Data Processing

To generate reliable data sets with desired spatial and temporal resolution, geospatial disaggregation, change mapping, and other spatiotemporal processing were carried out. 
Geospatial disaggregation refers to disaggregating and mapping the statistical data into geographical space with the help of ancillary geospatial data. For instance, the original population data was collected for each administrative unit and could be transformed into geospatial grid spaces through a correlation analysis of population and land use and building layers information [39]. Change mapping utilized multitemporal remotely sensed data to extract the changes of wetlands, forest, and built-up areas and generated time-series data, which were the basis for calculating indicators and assessing SDG goal(s) assessment with a geographical location perspective [40,41].

\section{(3) Data-Driven Indicator Calculation}

Three different methods were used for calculating or deriving the selected indicators from geospatial and statistical data sets. The first was to derive indicators directly from geospatial data (including remote sensed imagery) using spatial density calculation, land-cover classification, and others. The second calculated indicators directly from statistical data through ratio (or proportion), rate of change, index, or other calculations. The third one utilized both statistical and geospatial data with the help of quantitative measurement of spatiotemporal accessibility, coverage, relations, and others.

\section{(4) Evidence-Supported Progress Assessment}

The quantified indicators, multitype facts (data and local practices), and other evidences were used to assess the progress toward SDGs at three different levels. First, every indicator was aligned with internationally and/or nationally recognized criteria or references (see Section 4.1) and then given a rank with four grades. Second, each local SDG was assessed through a focused analysis on the achievement and characteristics, as well as existing problems. Last, three SDG clusters (i.e., economy, environment, and society) were analyzed, respectively, to derive an overall picture of the economic growth, social inclusion, and natural beauty, as well as their coherency.

\section{(5) Study Area}

The pilot study area was Deqing County, which is located in the northeast part of the Zhejiang Province, P. R. China (Figure 2), with an area of $936 \mathrm{~km}^{2}$ and a population of about 440,000. It belongs to the Yangtze River Delta, and the subtropical humid monsoon climate creates four clear seasons with warm and humid weather, and annual average temperature of $17.2^{\circ} \mathrm{C}$. With a topography higher in the west and lower in the east, its land cover can be characterized as " $50 \%$ mountain, $10 \%$ water and $40 \%$ farmland", forming a livable place with mountains in view and waters in sight. The county is adjacent to the north of Hangzhou and to the west of Shanghai and takes only 13 min to Hangzhou from Deqing by high-speed train, and less than $2 \mathrm{~h}$ by car to most major cities in the Yangtze River Delta region (such as Shanghai, Ningbo, and Nanjing). Deqing County has a long tradition in practicing the concepts of sustainable development and has a solid foundation of geospatial and statistical information.
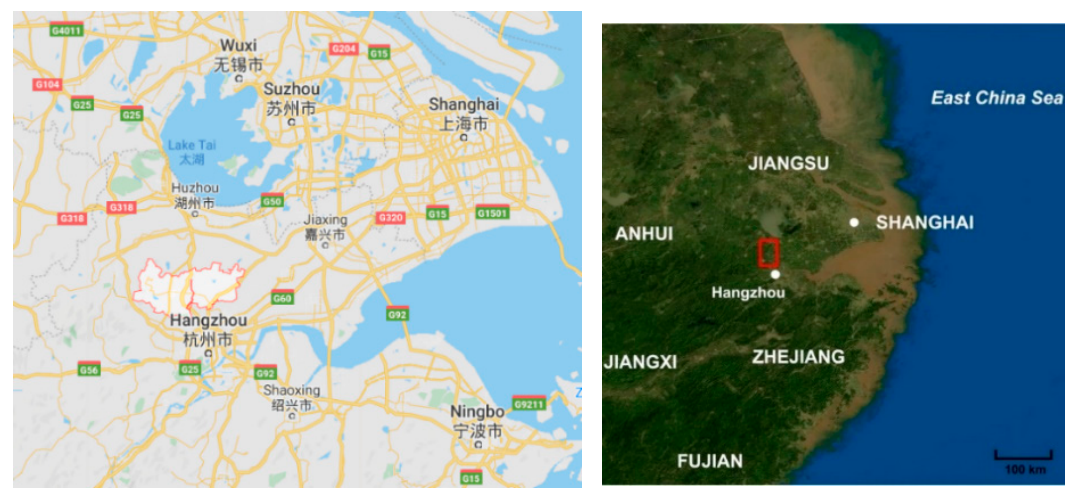

Figure 2. Geographical location of Deqing County (extracted from Google Maps). 


\section{Comprehensive Measurement of SDGs with a Geographic Lens}

\subsection{Adoption of 102 Indicators with an AERS Strategy}

In Section 2, it was pointed out that the SGIF was designed for measurement at a national level, and a localization analysis was provided to tailor the SGIF to local circumstance. In this study, an AERS (Adoption, Extension, Revision, and Substitution) strategy was developed for the localization of indicators. In the end, a set of 102 indicators were adopted for assessment, as shown by Table 1.

Table 1. The 102 indicators used for the Deqing study *.

\begin{tabular}{cccl}
\hline SDG & Num. of SGIF Indicators & Num. of Deqing Indicators & \multicolumn{1}{c}{ Indicators } \\
\hline 1 & 14 & 5 & $1.1 .1 ; 1.3 .1 ; 1.4 .1 ; 1$. a.2 $; 1$. b. 1 \\
2 & 13 & 9 & $2.1 .1 ; 2.1 .2 ; 2.2 .1 ; 2.2 .2 ; 2.3 .1 ; 2.3 .2 ; 2.4 .1 ; 2 . a .1 ; 2 . c .1$ \\
3 & 27 & 15 & $3.1 .1 ; 3.1 .2 ; 3.2 .1 ; 3.2 .2 ; 3.3 .1 ; 3.3 .2 ; 3.3 .3 ; 3.3 .4 ; 3.4 .1 ;$ \\
4 & 11 & 7 & $3.6 .1 ; 3.7 .1 ; 3.8 .1 ; 3 . b .1 ; 3 . b .2 ; 3 . c .1$ \\
5 & 14 & 4 & $4.1 .1 ; 4.2 .2 ; 4.3 .1 ; 4.5 .1 ; 4.6 .1 ; 4 . a .1 ; 4 . c .1$ \\
6 & 11 & 7 & $5.1 .1 ; 5.5 .1 ; 5.5 .2 ; 5 . c .1$ \\
7 & 6 & 3 & $6.1 .1 ; 6.2 .1 ; 6.3 .1 ; 6.3 .2 ; 6.4 .1 ; 6.4 .2 ; 6.6 .1$ \\
8 & 17 & 6 & $7.1 .1 ; 7.1 .2 ; 7.3 .1$ \\
9 & 12 & 9 & $8.1 .1 ; 8.2 .1 ; 8.5 .2 ; 8.6 .1 ; 8.9 .1 ; 8.9 .2$ \\
10 & 11 & 2 & $9.1 .1 ; 9.1 .2 ; 9.2 .1 ; 9.2 .2 ; 9.3 .1 ; 9.5 .1 ; 9.5 .2 ; 9 . b .1 ; 9 . c .1$ \\
11 & 15 & 9 & $10.1 .1 ; 10.2 .1$ \\
12 & 13 & 5 & $11.1 .1 ; 11.2 .1 ; 11.3 .1 ; 11.4 .1 ; 11.5 .1 ; 11.5 .2 ; 11.6 .1 ;$ \\
13 & 8 & 4 & $11.6 .2 ; 11.7 .1 ;$ \\
15 & 14 & 7 & $12.2 .2 ; 12.4 .2 ; 12.5 .1 ; 12.6 .1 ; 12.7 .1$ \\
16 & 23 & 5 & $13.1 .1 ; 13.1 .3 ; 13.3 .1 ; 13.3 .2$ \\
17 & 25 & 5 & $15.1 .1 ; 15.1 .2 ; 15.2 .1 ; 15.3 .1 ; 15.4 .1 ; 15.4 .2 ; 15 . a .1$ \\
Total & 234 & 102 & $16.1 .1 ; 16.1 .3 ; 16.3 .2 ; 16.5 .1 ; 16.6 .1$ \\
\hline
\end{tabular}

Note: * The table is the result of the localizing indicators using an Adoption, Extension, Revision, and Substitution (AERS) strategy from the SDGs Global Indicator Framework (SGIF). The details of the 102 indicators can be found from our website: http://www.deqing-sdgs.cn/Download.aspx?language=en.

- Adoption means that the original indicator, including metadata (the indicator name, definition, and calculation method), was not changed. An example is indicator "3.2.1: Under-five mortality rate". The definition is same as the statistical yearbook [42] and the numerical values can be used directly. There were 47 indicators of this type (i.e., adoption).

- Extension means that the name, definition, and calculation method of the original indicator were basically applicable, but the connotation or calculation method was extended somehow. There were six indicators in this category. An example is indicator "6.6.1: Change in the extent of water-related ecosystems over time". Based on its definition, it was extended into four sub-indicators to quantitatively describe this indicator, i.e., (a) rate of change in the spatial extent of water-related ecosystems; (b) rate of change in the water quantity characteristic of water-related ecosystems; (c) rate of change in the water quality of water-related ecosystems; (d) health status of the typical wetland ecosystem.

- Revision was to modify the calculation method of the indicator in order to better satisfy the needs of local SDGs monitoring. Forty-two indicators were revised. An example is indicator "3.8.1 Coverage of essential health services". The original definition contained multiple aspects which were too complicated for a county. Therefore, the definition was revised to how fast people can access health services with geospatial view.

- Substitution took place when the original indicator was not applicable. In this case, a new indicator was proposed. Seven indicators were substituted. An example is indicator "2.3.2: Per capita disposable income of rural residents". The original indicator was the average income of small-scale food producers by sex and indigenous status with no metadata, which was substituted according to the local characteristics. 
These indicators provided a full cover of all 16 SDGs, except the Goal 14 "Life Below Water", which is related to ocean, as Deqing is an inland county. This ensured a comprehensive measurement and analysis of the progress toward SDGs. Metadata were developed for each of the 102 indicators, including their definition, calculation method, and data requirements.

\subsection{Geospatial Di-aggregation and Change Mapping}

More than 200 types of statistical and geospatial data were collected in this case study. The main source of statistical data was local authoritative publications, such as the County Annual Statistical Bulletin, County Government Work Report, and the Water Resources Bulletin. The fundamental geospatial data were collected from the Deqing Geographic Information Centre, including vector data, digital elevation model (DEM), land cover, and remote sensing images.

The original population census data were collected for each administrative unit. As there are only 12 towns in Deqing, the spatial variation details of population are largely smoothed, making it difficult to examine its geographic distribution and pattern (Figure 3a). In this study, population was estimated according to heights and sizes of buildings, and population density at 30-m spatial resolution was then generated $[39,43,44]$. The results of the geospatially disaggregated population density are given by Figure $3 \mathrm{~b}$, where more spatial details about the population distribution pattern can be observed. It will serve as an important data set for measuring indicators and goals with a geospatial lens.
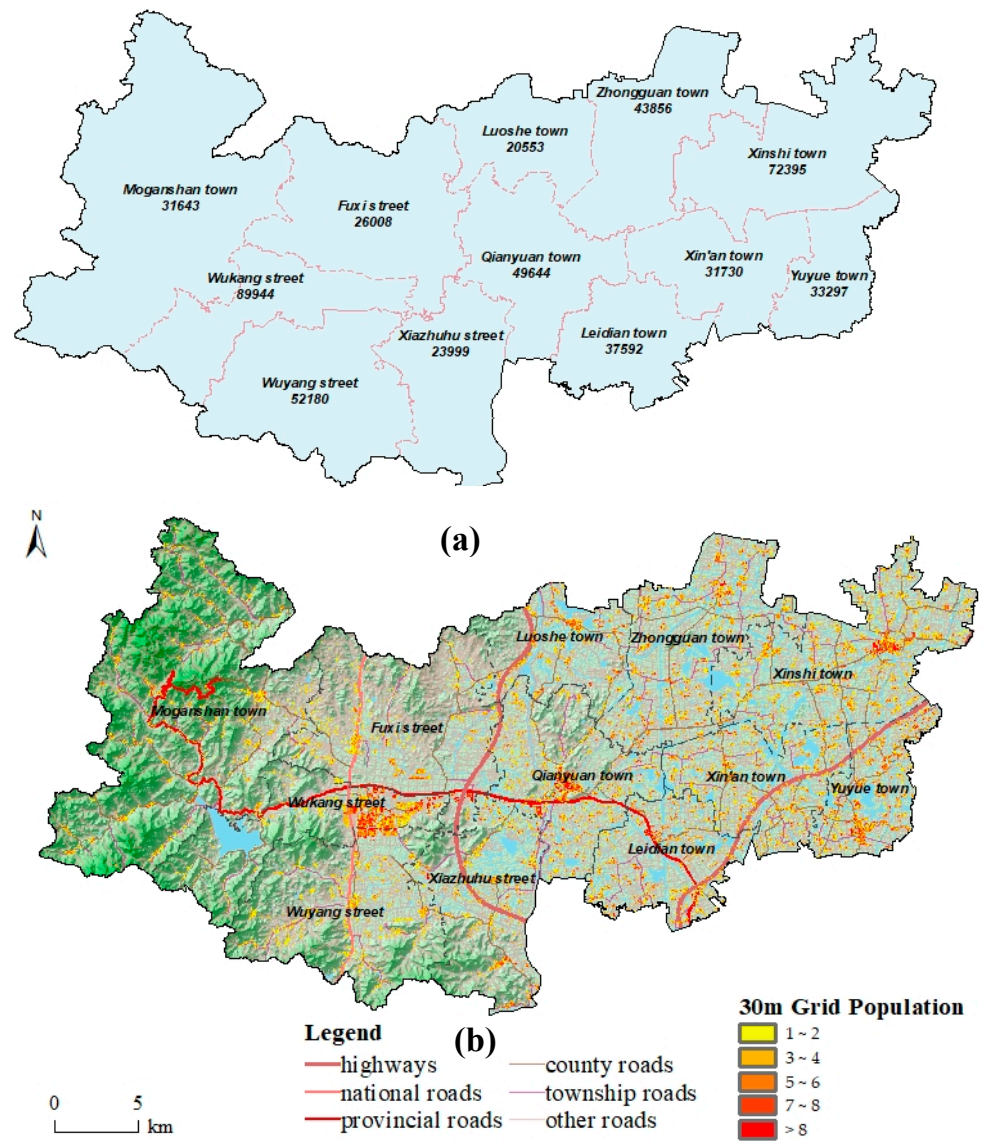

Figure 3. Geospatial disaggregation of population census data. (a) Administrative unit-based population data; (b) 30-m population density with topographic information.

Multitemporal remotely sensed images were used for land cover change mapping. For instance, Landsat images over last 30 years were collected and processed to derive wetland changes of Xiazhu Lake, the major wetland park of the county. Based on long-term Landsat satellite data, considering different types of water bodies and different meteorological conditions, a long-term series water sample 
library was established. According to the characteristics and needs of different regions, the sample library was automatically matched according to certain rules, and machine learning algorithms (such as random forest) were used to achieve fast and automatic extraction of long-term water resources information. Figure $4 \mathrm{a}$ gives the results of wetland changes in dry seasons and wet seasons, which are fundamental data for SDG 6 and indicator 6.6.1. Figure 4b,c illustrate, respectively, the mapping results of built-up areas and forest of the county.

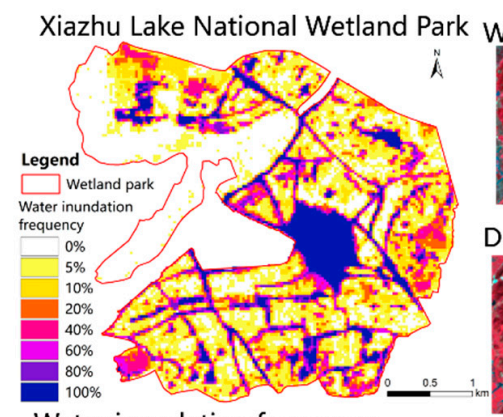

(a)

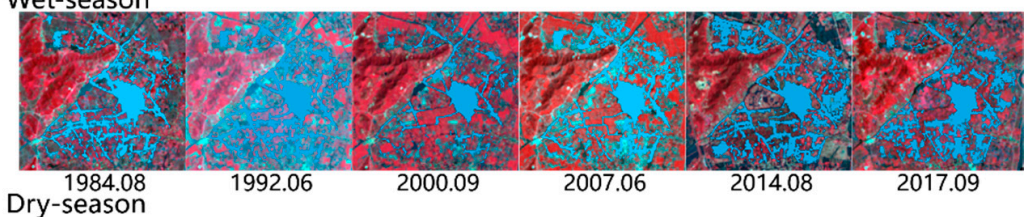

Water inundation frequency
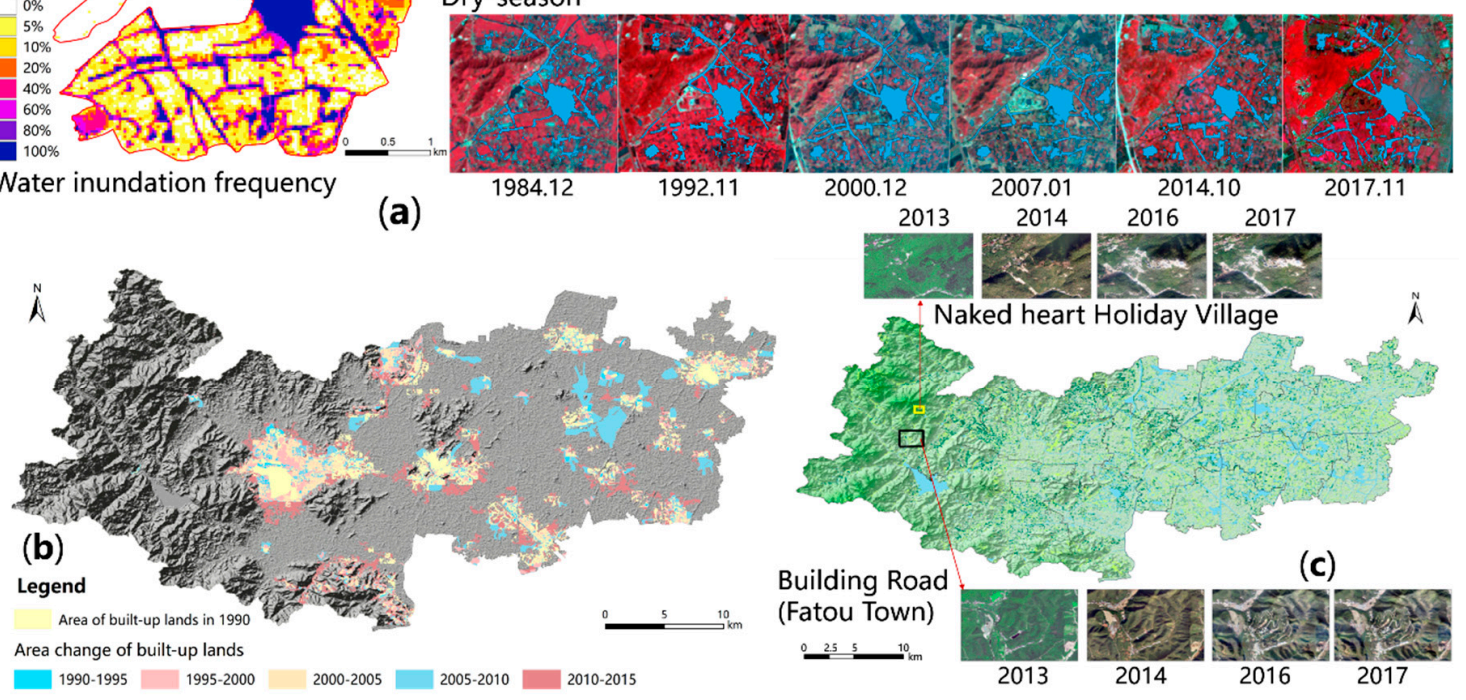

Figure 4. Change mapping with multitemporal remotely sensed images. (a) Wetland change (1984-2017);

(b) change of build-up area (1990-2015); (c) forest change (2013-2017).

Similarly, the change information of forest and built-up areas for Goals 11 and 15 was derived from multitemporal image data sets. For instance, from 2012 to 2017, the total forest coverage extracted from Landsat images remained stable at over $40 \%$ in Deqing County [41]. However, owing to the constructions of upscale homestay and road, the forest covers in some areas slowly declined, such as the Mogan Mountain, which is a famous tourist attraction in China and an ecologically sensitive area (Figure 4c).

\subsection{Measuring Local Indicators with a Geospatial Lens}

With the ready-to-use data, the 102 indicators were measured in three different ways. Eighty-six indicators were computed from statistical data, and 16 indicators were derived with the help of geospatial information, as shown in Table 2. Among them, nine indicators (e.g., 6.6.1, 15.1.1) were derived from geospatial data, and the remaining seven indicators (e.g., 11.3.1, 3.8.1) were measured by integration of statistical with geospatial data. It should be noted that different sub-indicators (indices) for a compound indicator may be computed in very different ways. For instance, 9.1.1b (Road density) was derived directly from road network data, but 9.1.1a (Proportion of rural population living within $2 \mathrm{~km}$ of an all-season road) was derived through the combination of geospatial (road network) and statistical data (population).

Figure 5 gives an example of how to derive indicator 1.4.1 with the combination of geospatial and population density data. Spatial accessibility was computed on the basis of disaggregated population density with 30-m resolution. Based on the urban road network data and the distribution data of basic service, a road network analysis model was established to calculate the convenience of basic 
service. Finally, combined with the population density, the evaluation result with "spatial and temporal coordinates" was formed, and the index calculation result was dynamically expressed.

Table 2. The 16 indicators derived using geospatial data.

\begin{tabular}{|c|c|c|c|}
\hline No & & Indicator & Type $^{1}$ \\
\hline 1 & 1.4 .1 & Population and proportions living in households with access to basic services & A \\
\hline 2 & 2.4 .1 & Proportion of agricultural area under productive and sustainable agriculture & B \\
\hline 3 & 3.8 .1 & Coverage of essential health services & A \\
\hline 4 & 6.2 .1 & Proportion of population using safely managed sanitation services & A \\
\hline 5 & 6.3 .2 & Proportion of bodies of water with good ambient water quality & $\mathrm{B}$ \\
\hline 6 & 6.6 .1 & $\begin{array}{l}\text { a Change in the extent of water-related ecosystems over time } \\
\mathrm{d} \text { Health status of the typical wetland ecosystem } \\
\text { a Proportion of rural population living within } 2 \mathrm{~km} \text { of an all-season road }\end{array}$ & A \\
\hline 7 & 9.1 .1 & $\begin{array}{l}\mathrm{b} \text { Road density } \\
\mathrm{c} \text { Weighted average travel time }\end{array}$ & A \\
\hline 8 & 11.2.1 & $\begin{array}{l}\text { Proportion of population that has convenient access to public transport, by sex, age and persons } \\
\text { with disabilities }\end{array}$ & A \\
\hline 9 & 11.3 .1 & Ratio of land consumption rate to population growth rate & A \\
\hline 10 & 11.7.1 & $\begin{array}{l}\text { Average share of the built-up area of cities that is open space for public use for all, by sex, age, and } \\
\text { persons with disabilities }\end{array}$ & B \\
\hline 11 & 15.1 .1 & Forest area as a proportion of total land area & B \\
\hline 12 & 15.1 .2 & $\begin{array}{l}\text { Proportion of important sites for terrestrial and freshwater biodiversity covered by protected areas, } \\
\text { by ecosystem type }\end{array}$ & B \\
\hline 13 & 15.2.1 & Proportion of forest change & B \\
\hline 14 & 15.3 .1 & Proportion of land that is degraded over total land area & B \\
\hline 15 & 15.4 .1 & Protected area coverage of import. sites for mountain biodiversity & B \\
\hline 16 & 15.4 .2 & Mountain vegetation cover & B \\
\hline
\end{tabular}

Note: ${ }^{1}$ Type A means calculating by combined statistical and geospatial data, type B is only using geospatial data.

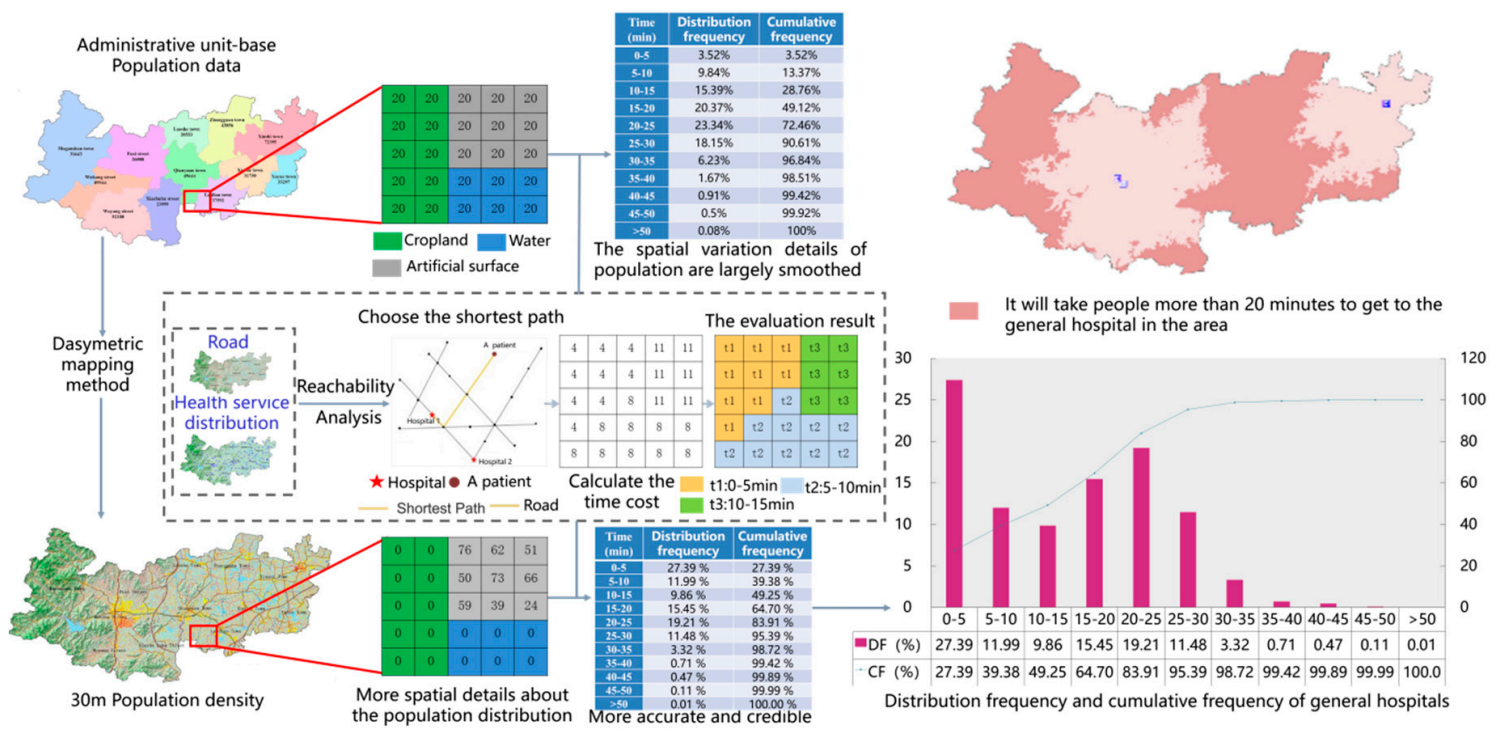

Figure 5. Deriving indicator 1.4.1 with a geospatially disaggregated data.

\section{Comprehensive Assessment of SDG Indicators at Three Levels}

\subsection{Ranking of Indicators}

The indicators were aligned with the international or national benchmarks (recognized criteria or references) and were ranked by a four-score scheme, with a color for each score. The first rank was green, meaning basically fulfilling the requirements of the indicator; the second rank was yellow, standing for being upgraded; the third rank was orange, which demonstrated facing challenges; and the bottom rank was red, showing the result was far from achieving the 2030 indicator requirements. Table 3 takes SDG 6 as an example and demonstrates how its seven local indicators were ranked. 
Table 3. Calculating and ranking SDG 6 indicators.

\begin{tabular}{|c|c|c|c|}
\hline Indicators & Quantitative Result & Evaluation Reference & \\
\hline 6.1.1 Proportion of population using safely managed drinking water services & $\begin{array}{l}\text { Urban: } 100 \% \\
\text { Rural: } 99.6 \%\end{array}$ & Green: $\geq 98 \%$ & I \\
\hline $\begin{array}{l}\text { 6.2.1.a Penetration rate of sanitary toilets in rural areas } \\
\text { 6.2.1.b Service convenience of urban public toilets }\end{array}$ & $\begin{array}{l}98 \% \\
\text { From all parts of town, the nearest public toilet can be reached within } 16 \mathrm{~min}\end{array}$ & Green: $\geq 95 \%$ & I \\
\hline \multirow{3}{*}{ 6.3.1 Proportion of wastewater safely treated } & Urban domestic sewage: $91.06 \%$ & \multirow{3}{*}{$\begin{array}{l}\text { Municipal domestic sewage: } 92.4 \% \text {; } \\
\text { Coverage rate of the treatment of domestic wastewater (upper-middle-income } \\
\text { countries):59\% }\end{array}$} & IV \\
\hline & Rural domestic sewage: $80.68 \%$ & & \multirow[t]{2}{*}{ III } \\
\hline & Trade effluent: N/A & & \\
\hline 6.3.2 Proportion of bodies of water with good ambient water quality & $68.75 \%, 100 \% * * *$ & $76.9 \%$ & IV \\
\hline 6.4.1 Change in water-use efficiency over time & $\begin{array}{l}\text { The water consumption per } 10,000 \mathrm{CNY} \text { of GDP in } 2017 \text { was } 65.7 \mathrm{~m}^{3} \text {, dropped } \\
23.52 \% \text { from } 2015\end{array}$ & By 2020 , the efficiency of water use will be $23 \%$ lower than that of 2015 & II \\
\hline $\begin{array}{l}\text { 6.4.2 Level of water stress: freshwater withdrawal as a proportion of available } \\
\text { freshwater resources }\end{array}$ & $25.08 \%$ & $\begin{array}{l}\text { Green: } \leq 25 \% \\
\text { Yellow: } 25 \%<x \leq 50 \%\end{array}$ & I \\
\hline $\begin{array}{l}\text { 6.6.1 Change in the extent of water-related ecosystems over time } \\
\text { 6.6.1.a Rate of change in the spatial extent of water-related ecosystems }\end{array}$ & $\begin{array}{l}6.47 \% \\
11.14 \%\end{array}$ & $\begin{array}{l}\text { 0-20\%: Highly sustainable; } \\
\text { 21-40\%: Locally sustainable but threatens global stability; }\end{array}$ & IIII \\
\hline 6.6.1.b Rate of change in the water quantity characteristic of water-related ecosystems & $8.26 \%$ & 41-60\%: Border-line sustainability. Corrective actions are strongly recommended; & III \\
\hline $\begin{array}{l}\text { 6.6.1.c Rate of change in the water quality of water-related ecosystems } \\
\text { 6. }\end{array}$ & & 61-100\%: Unsustainable Urgent renewal is required. & \\
\hline 6.6.1.d Health status of the typical wetland ecosystem & Xiazhu Lake wetland: In good condition & & \\
\hline
\end{tabular}

6.6.1.d Health status of the typical wetland ecosystem

Xiazhu Lake wetland: In good condition

Note: The data in the table is 2016 data, except for ${ }^{* *}$ represents 2017 data. Metrics used for Comparing/ranking: I—SDGs Dashboard; II—National plan; III—Multiple evaluation;

IV—Others. Ranking Class: $\square$ 1st Quarter $\square$ 2nd Quarter $\square$ No ranking. 
The results of indicators 6.1.1, 6.2.1, and 6.4.2 were compared with the SDG indicator thresholds in the SDGs Index and Dashboard [45], which is an international benchmark released by the Bertelsmann Foundation and the United Nations Sustainable Development Solutions Network (SDSN). It was derived from the results of $157 \mathrm{UN}$ member states/regions by adjusting most indicators to the score range between 0 (lowest) and 100 (highest), and was marked as the reference category "I". The indicator thresholds are the same for all countries and were subject to extensive consultations with expert communities [45]. For instance, Green of SDG 6.4.2 (Level of water stress: freshwater withdrawal as a proportion of available freshwater resources) in the indicator thresholds was less than $25 \%$, and yellow was between $25 \%$ and $50 \%$. The result of water stress in Deqing was $25.08 \%$. Thus, the SDG6.4.2 was ranked as yellow.

The National Plan is the major nationally recognized benchmark, which defines a set of qualitative and quantitative requirements to be achieved by 2020 and 2030, respectively, and was marked as the reference category "II". For instance, the indicator threshold of SDG 6.4.1 was not available in the SDGs Index and Dashboard. Thus, a quantitative national criterion derived from the National Plan was adopted, which states that "by 2020, reduce the water consumption per CNY $¥ 10,000$ of GDP by $23 \%$ from 2015" [46]. Deqing reduced water consumption by $23.52 \%$ in 2017 . Thus, the SDG 6.4.1 was ranked as green.

In case of lacking international and national criteria, the world's advanced level and average level of a given indicator was used for comparison and assessment. It was marked as the reference category "III". For instance, SDG 6.6.1 relates to the spatial extent, water quantity, and water quality of the water-related ecosystems, and was calculated by the weighted averaging of the three categories. The extent to which the water-related ecosystem deviated from its natural state was $6.47 \%$. The SDG 6.6.1 was ranked as green through the comparison of the result and Ecological Classes, which was proposed by UNWATER and Kleynhans [47,48].

It should be noted that no appropriate benchmarks (references) were found for 23 indicators, such as the "Health state of the typical wetland ecosystems" of indicator 6.6.1. Such indicators were marked "gray" in Table 3. In addition, the "trade effluent" of indicator 6.3.1 was marked "gray" because of the unreliable and inconsistent data.

In total, 79 of the 102 indicators had comparable reference or criteria. Among them, 68 reached or almost reached the objectives of the United Nations Agenda 2030, as well as ranking top in China and even in the world (green). Nine indicators needed to be improved, and two indicators faced challenges.

\subsection{Evaluation of Individual Goals}

In order to derive meaningful assessment results, the original numerous targets of each SDG need to be grouped into 2 to 4 sub-sets with clearly implied meaning (or connotation), which can be considered as local targets. The evaluation or assessment of each SDG will be facilitated through a focused analysis of these local targets with the help of the quantified indicators, and other spatio-temporal evidences, such as multi-temporal images and maps, local knowledge and experiences. For instance, the original SDG 6 aims to "Ensure availability and sustainable management of water and sanitation for all", and has eight targets (https://www.un.org/sustainabledevelopment/water-and-sanitation/). It covers a number of topics ranging from drinking water (6.1) and sanitation (6.2), water quality (6.3) and water use efficiency (6.4), water resource management (6.5), protecting water-related ecosystems (6.6), international cooperation and capacity-building in water- and sanitation-related activities (6.a), as well as involvement of local communities (6.b). According to the local circumstance of Deqing County, they were grouped into three local targets with a clear connotation, i.e., safe drinking water and sanitation, water resources utilization and protection of water-related ecosystems (Figure 6).

"Safe drinking water and sanitation" focuses on equitable access to safe drinking water and sanitation services for all, including the provision of household piped water supplies rate and sanitary toilet services in rural, urban and public places. With the indicators 6.1.1 and 6.2.1, it can be observed that a full coverage of safely managed drinking water and sanitation service have been achieved 
through strictly implementing water environment function zoning and protecting drinking water source in the past years. After feces decontamination, the penetration rates of sanitary toilets in urban and rural areas reached $100 \%$ and $98 \%$ respectively. Now all the urban residents can get access to public toilets in $16 \mathrm{~min}$.

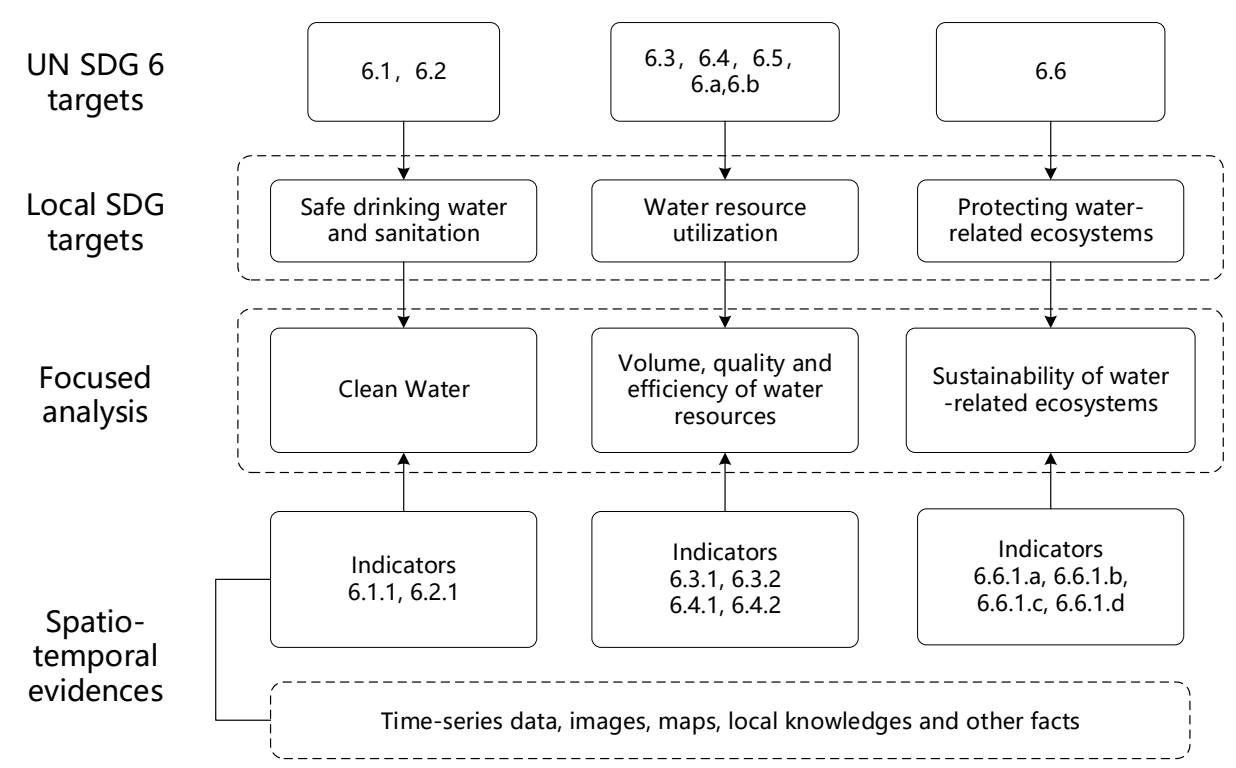

Figure 6. Assessment of local SDG 6 with spatiotemporal evidence.

"Water resources utilization" refers to water quality and water use efficiency, including water resources management, including total water resources, good water standard-reaching rate, water use efficiency, and water shortage pressure. With the integrated analysis of indicators 6.3.1, 6.3.2, 6.4.1, and 6.4.2, it can be shown that the total amount of water consumption has been well controlled through the strictest water resources management mechanism. The water quality of Deqing improved gradually from 2013 to 2017, and the water quality of all 34 major rivers in 2017 reached standard through wastewater treatment in urban and rural treated areas, shutting down the polluting aquaculture and industries with ecological compensation mechanisms, and rectifying the high-water consumption industries, such as printing and dying, papermaking, and the chemical industry. The efficiency of water utilization increased by 47.7\% from 2012 to 2016 through the construction of a water-saving society and by controlling pollution in agriculture and industrial areas.

"Protection of water-related ecosystems" focuses on the function change of water-related ecosystem over time (6.6.1), analyzing the sustainability of water-related ecosystem through the area, quantity, quality, and health status of the water-related ecosystem. With multitemporal imagery and statistical data, the extent to which the water-related ecosystem deviates from its natural state was estimated as $6.47 \%$ in the past 35 years. This means that the water-related ecosystem has been protected effectively. Indeed, the 10 sub-indicators related to water ecosystems (e.g., wetland water quality, water source assurance rate, soil heavy metal content, soil moisture content, biodiversity) have been comprehensively improved. For example, the soil conditions, water environment, and biodiversity/habitat of the Xiazhu Lake National Wetland Park, which is the largest natural wetland ecosystem in Southern China, are well maintained.

According to the comprehensive analysis of "Safe drinking water and sanitation", "Water resources utilization", "Protection of water-related ecosystems" and other relevant evidences or facts, the following were found: The full coverage of safely managed drinking water has been achieved, the proportion of good-quality water in the 34 major rivers had increased from $13.3 \%$ in 2013 to $100 \%$ in 2017, and the health conditions of the water-related ecosystems have been greatly enhanced. However, in view of the current level of water stress, the county still a certain degree of potential water shortage. 
Based on the above quantitative evaluation of indicators, a single goal was ranked according to the principle of "minimum factor", and the degree of realization of each goal was determined by the degree of realization of the lowest indicator in the goal. In this case, the SDG 6 was ranked as the second class (as yellow, need to be improved), as shown by Figure 7. In total, eight SDGs reached standard (green), six SDGs needed improvement (yellow), and only two SDGs (SDG 11 and SDG 17) faced challenges (orange). There was no significant gap between Deqing's goals and that of the 2030 Agenda (no red).

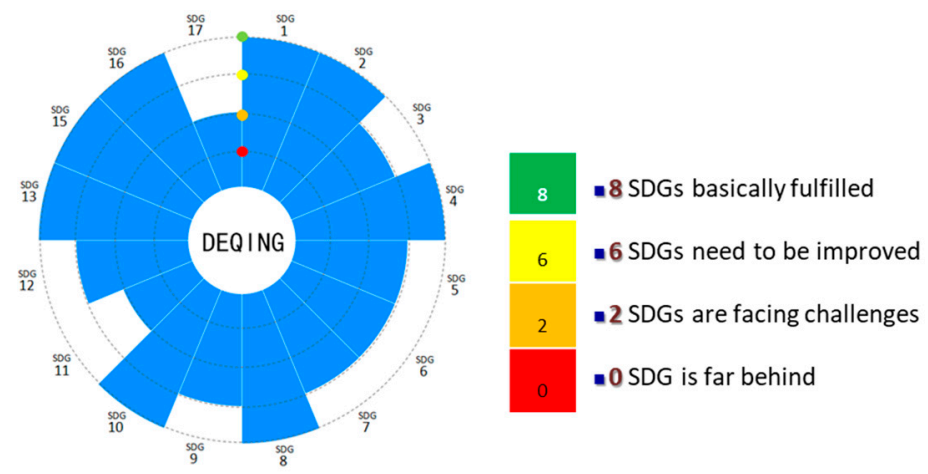

Figure 7. Assessment result of all the 16 individual SDGs in Deqing.

\subsection{Evaluation of Goals in Three Clusters}

All the major SDGs were grouped into three clusters-environmental, economic, and social-according to the contribution or relevance of their indicators, as shown in Figure 8 . The economic cluster included five SDGs (Goal 2, 7, 8, 9, and 10). The environmental cluster included five SDGs (Goal 6, 12, 13, 14, and 15). The social cluster includes 12 SDGs (Goal 1, 2, 3, 4, 5, 6, 7, 8, 9, 10,11 , and 16). It should be noted that a single SDG may be allocated to two or three goal clusters. For instance, SDG 2 and SDG 8 were grouped into both the economic and social cluster, and SDG 6 was grouped into both the social and environmental cluster. SDG 7 fell into all the three clusters due to the contribution of their individual targets or related indicators.

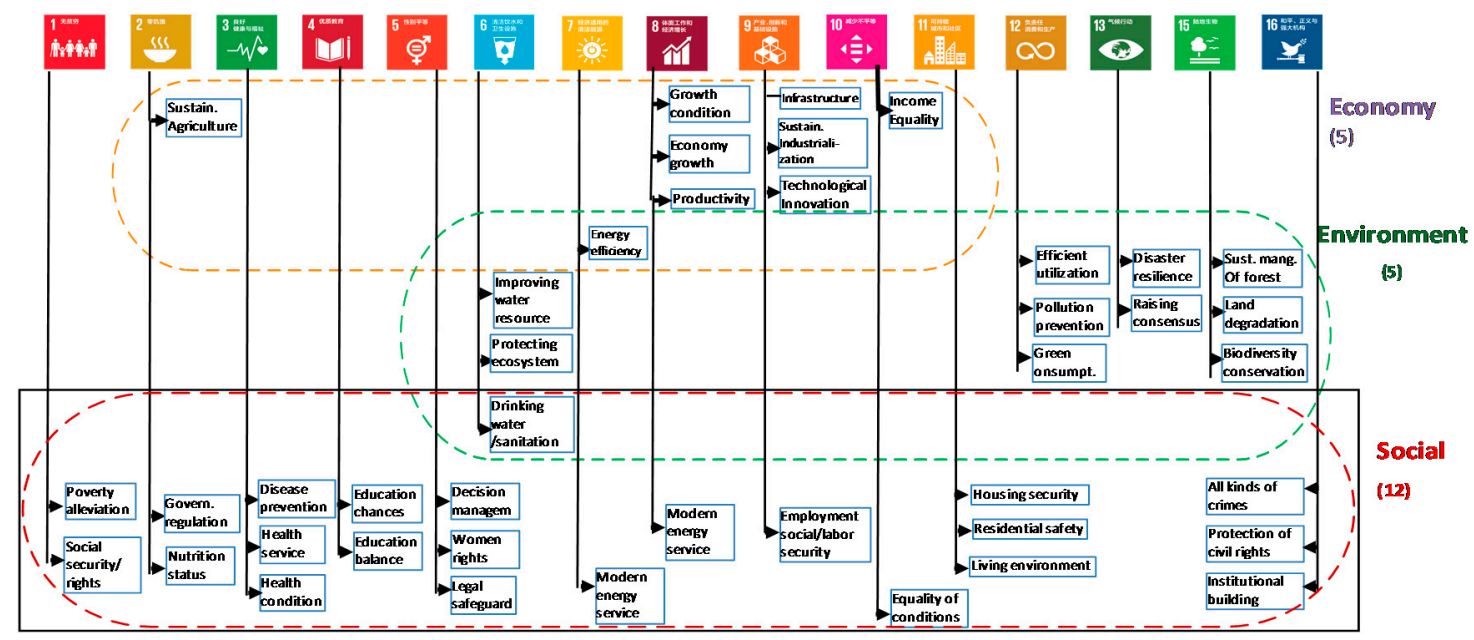

Figure 8. Three goal clusters and their affiliated targets.

A set of key elements or analysis priorities were further defined for each SDGs cluster. For instance, the analysis of the economic SDGs cluster focused on economic growth conditions, economic growth trends, and economic development. For the environmental SDGs cluster, the analysis focused on resource use, ecological environmental protection, and regional responses to climate change. For the 
social SDGs cluster, analysis focused on how the three basic needs (survival, security, and development) are met.

Figure 9 explains how the focused analysis was implemented for the environmental goal cluster. The rational utilization of resources was analyzed though energy efficiency, water resources improvement, efficient use, and water-related ecosystems protection. Ecology and environment were analyzed through pollution prevention, green consumption, sustainable management of forests, measures for curbing land degradation and biodiversity conservation, and effects of human protection of ecological environment. Human regional response to climate change was analyzed through the ability of disaster resilience and the penetration of awareness.

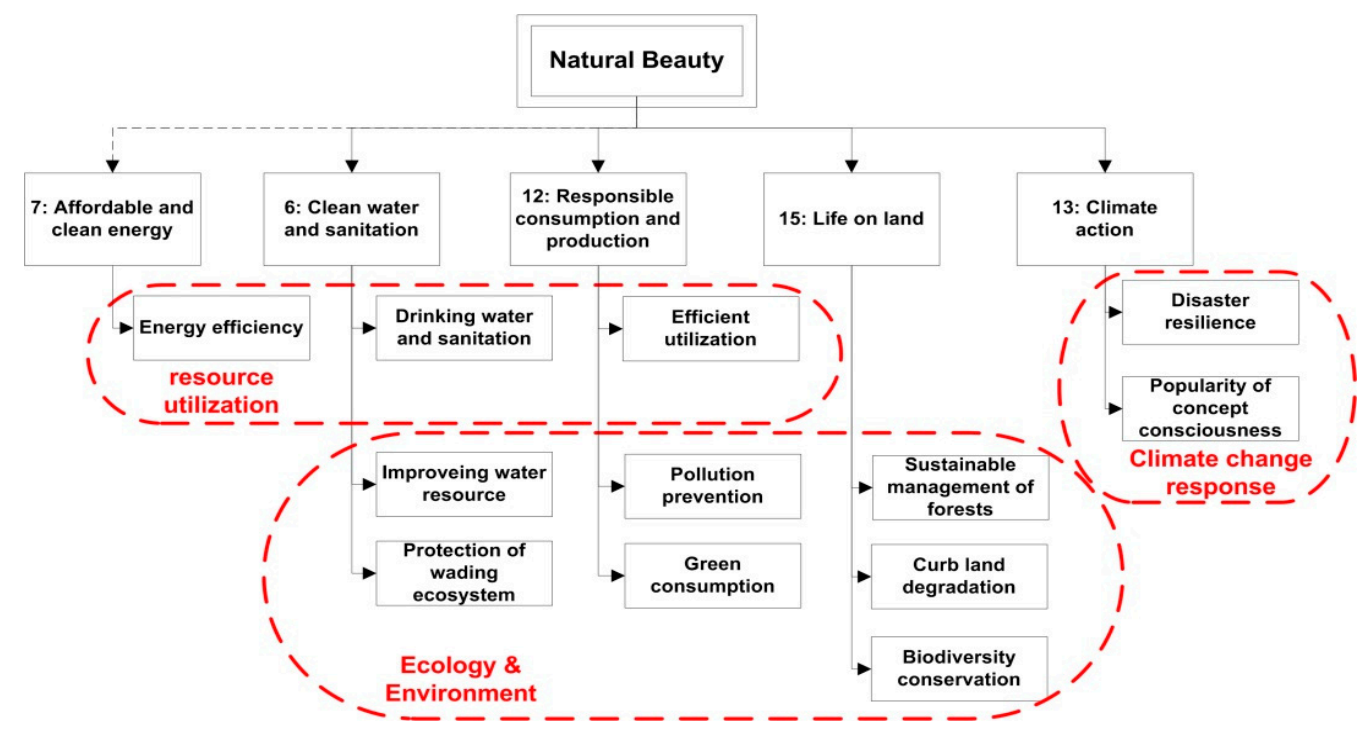

Figure 9. Focused analysis of environmental SDGs cluster in Deqing.

SDGs are integral and inseparable. The good coordination within each SDG cluster and among three SDG clusters is an important sign to measure the progress toward sustainability. According to the indicator rating and the results of the single SDG assessment, the degree of coordination of each SDG cluster was calculated through the mean $(\mu)$, standard deviation $(\sigma)$, and coefficient of variation (C.V.) (Figure 10). The C.V. is defined as the ratio of the standard deviation $(\sigma)$ to the mean $(\mu)$ [49]. It reflects the fluctuation of the goals evaluation in each field-the smaller the value, the smaller the fluctuation. The variation coefficient of three clusters were $0.091,0.106$, and 0.102 , respectively. This indicates there is a good coordination among the three SDGs clusters (economy, environment, and society), with the economic cluster having the highest degree of stability and coordination. The higher coordination will help Deqing to aid the achievement of other SDGs.

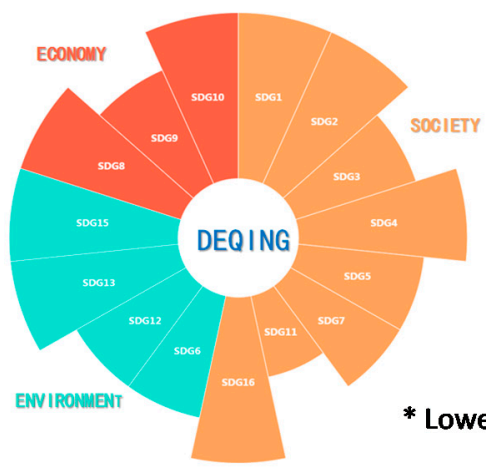

\begin{tabular}{|l|c|c|c|}
\hline & $\mu$ & $\sigma$ & C.V. \\
\hline Economic cluster & 3.867 & 0.352 & 0.091 \\
\hline $\begin{array}{l}\text { Envi ronmental } \\
\text { cluster }\end{array}$ & 3.810 & 0.402 & 0.106 \\
\hline $\begin{array}{l}\text { Social cl uster } \\
\text { lo }\end{array}$ & 3.872 & 0.397 & 0.102 \\
\hline
\end{tabular}

Figure 10. Assessment result of three SDG clusters in Deqing. 


\subsection{Overall Assessment}

Deqing County has made significant economic and social advances while maintaining a good ecological environment over the past few years. Good progress has been achieved in urban and rural development, balanced development, and green development.

One good example is the story of the Crested Ibis (Zhu Huan), one of endangered bird species in the world, which demands a high-standard living environment. Deqing was one of the native regions of the Crested Ibis (Figure 11). However, the wild Crested Ibis disappeared from Deqing in the late 1950s, due to the deterioration of the local ecological environment. For the past 15 years, 1720 rural domestic sewage treatment terminals have been established, covering $99.25 \%$ of administrative villages. In addition, $99 \%$ of the pig farm and polluting aquaculture have been shut down or terminated. In 2014, after the improvement of ecological environment and in situ conservation, 33 Crested lbises returned to the wild state in the Xiazhu Lake. At present, the total population of Crested Ibis in the Xiazhu Lake has reached 323. The long-awaited Crested Ibis eventually has come home and settled in Deqing.
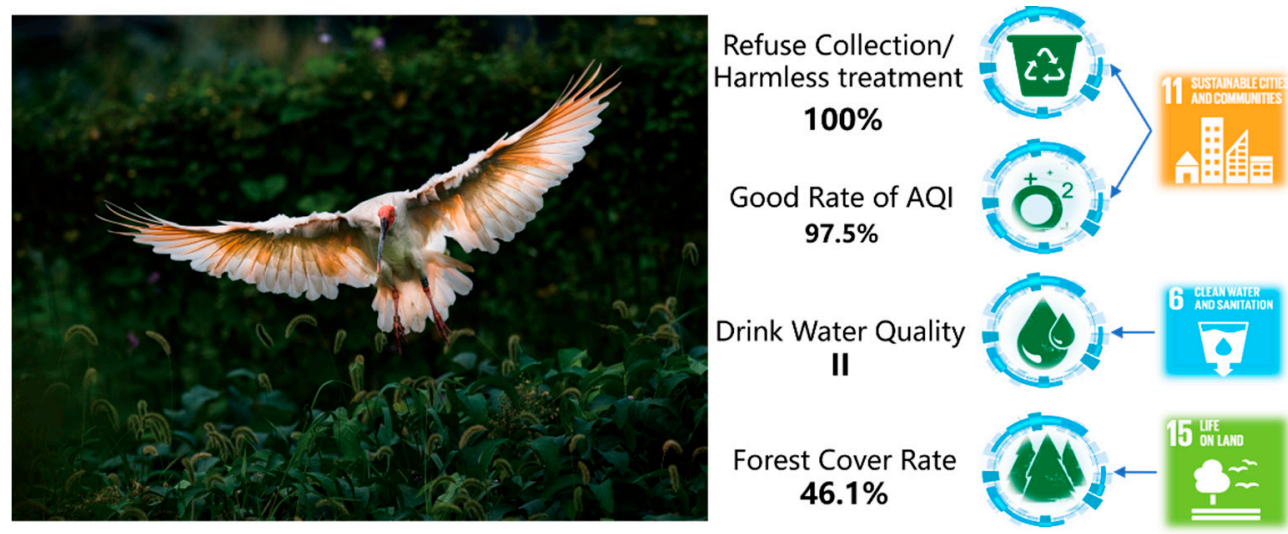

Figure 11. Home-back of Crested Ibis (Courtesy of the Government of Deqing County).

From the assessment data, it also noted that there is still room to improve. For example, the industrial emission should be further reduced, the energy consumption and material consumption should be lessened, the public transport convenience and other aspects need to be further improved, and the stability and coordination degree between the environmental sector and social sector are slightly inadequate.

\section{Discussion: Lessons Learned and Experience Gained}

It was found that the success of such a comprehensive SDGs measurement depends largely on a number of enabling conditions, such as the determination of local indicators and SDGs targets, availability of reliable geospatial information, moving to transformative actions, and the engagement of stakeholders and innovative partnerships [50].

\subsection{Discussion: Lessons Learned and Experience Gained}

Originally, SGIF was designed for tracking SDGs progress at national level. When applied to county (or local) level, a good number of the indicators may not be suitable. This makes it difficult to provide a full and rational coverage of all the primary SDGs of the study area. It is therefore imperative to conduct appropriate revision, extension, and even substitution. In the Deqing case, more than $53 \%$ indicators were determined through extension, revision, and substitution. This made the determination of the local indicators a particularly challenging task, and demanded an interactive collaboration among sustainability scientists, statistical staff, and geospatial information experts.

Another challenge is from the available benchmarks (references or criteria) used for the ranking of selected indicators. Currently, the SDGs dashboard and the National Plan mandate requirements 
are the major references or criteria available. However, appropriate references or criteria could not be found for about $22 \%$ of the indicators in the Deqing case study. Besides, some references of the SDGs dashboard were found not suitable for developing countries and local scales. It is therefore necessary to explore and develop objective evaluation criteria for local SDGs studies.

Moreover, each SDG goal has many targets and makes it difficult to derive meaningful results of evaluation or assessment. A localization of SDG targets was implemented in the Deqing case by grouping the original SDGs targets into two to four local targets with clearly implied connotation. This facilitated the focused analysis of the achievement and existing problems for each of the 16 individual SDGs. The development and formalization of such a localized approach to SDG targets through connotation analysis needs to be taken into consideration in further investigations.

\subsection{Availability of Reliable Geospatial Information}

Geospatial information plays an irreplaceable role in measuring and monitoring the progress toward SDGs, such as disaggregating population census data in geographic space, providing geospatial parameters (accessibility, coverage, etc.), deriving SDGs indicators, and supporting the evidence-based qualitative analysis and location-based visualization. Without the utilization of geospatial information, a SDGs measurement and monitoring would not be 'comprehensive', as some indicators or targets can only be derived or analyzed from a geospatial lens. On the other side, this will demand more significant resources to prepare and make best use of geospatial information.

As far the Deqing case study is concerned, the county has been proactive to develop its geospatial infrastructure and related industries in the last 10 years. Multiscale and multitype geospatial databases have been put into place and a variety of value-added geospatial applications have been developed. This has facilitated the collection and preprocessing of the geospatial information in the Deqing pilot project, which was completed within a one-year period.

The availability and utilization of reliable and up-to-date geospatial information remains a big challenge for SDGs measurement and monitoring in large area. More automatic and operational techniques should be developed, such as the high-reliability computing of land cover and other core geospatial data, as well as the use of social media and other crown sourcing data.

\subsection{Moving to Transformative Actions}

With the results of this comprehensive measurement, an overall picture was created regarding how far Deqing County is from the 2030 SDGs. This helps local people gain a better understanding of where they stand and what the gaps are. A five-year action plan has been formulated by the local government to translate the 2030 Agenda into its own development vision and priorities, including a roadmap, implementation strategies, and monitoring mechanisms. Tangible actions have been planned with allocated resources to address the gaps and challenges, such as reducing industrial emissions, lessening energy consumption and material consumption, improving public transport convenience, etc.

Having identified the role of measurable indicators as a management tool, the county resolved to carry out regular monitoring and reporting of SDGs implementation performance. A dynamic monitoring mechanism is to be established. There are a number of items to be explored, including the design of key variables for regular monitoring, use of social media and other big data, problem diagnosis, and policy simulation.

\subsection{Engagement of Stakeholders and Innovative Partnership}

The measurement and monitoring of the progress toward 2030 SDGs is a complex and open process that requires constructive engagement of scientific, users, policy, and other communities. First of all, researchers from seven research institutions and universities formed a multidisciplinary task force, covering sustainability, earth science, geography, remote sensing, and geoinformation, statistics, and computer sciences. This enabled the integration of knowledge from different disciplines in the process of indicator adoption, geospatial-enabled computation, and evidence-based assessment. 
A strong multi-stakeholder engagement was received from more than 20 local governmental agencies, local communities, and other organizations of Deqing, such as the statistical office, planning department, etc. This injected considerable resources and support to the pilot study, including the identification of user requirements, provision of fundamental data sets, adoption of local indicators, and devising of local transformative actions.

Moreover, during the project preparation and execution, a group of high-level national and international experts was invited to provide constructive advice through over 20 meetings. Some of the experts come from the United Nations Statistics Division (UNSD), Ministry of Natural Resources of China, and National Bureau of Statistics of China. With the help of National Bureau of Statistics of China, several special meetings were convened to discuss the adoption of appropriate indicators and ranking of the results. A special session was organized jointly with UNSD during the first United Nations World Geospatial Congress to present and dissimilate the outputs of this pilot project.

\section{Conclusions}

This paper presents a story about the comprehensive measurement of SDGs in Deqing. In this study, 102 indicators were adopted and/or adapted for the assessment with the assistance of geospatial data. Analysis has been carried out at three levels, i.e., individual indicators, individual goals, and goals in three clusters. It was found that Deqing performs very well. With a total of 79 of the 102 indicators compared with benchmarks, 68 indicators reached or were very close to the objectives of the United Nations Agenda 2030, nine indicators needed improvement, and only 2 indicators faced challenges. At the SDG level, eight SDGs reached standards, six SDGs needed to be improved, and only two SDGs faced challenges. At the overall development level, the stability of the three clusters (economy, environment, and society) and the overall system of sustainable development were relatively high.

This paper shows that the overall SDGs progress at a local context can be well measured through developing a set of indicator-based, data-driven, and evidence-supported approaches with a geographic perspective and establishing a cooperative partnership among all stakeholders to mobilize resources. The geospatial information plays an irreplaceable role and assures a 'comprehensive' SDGs measurement and monitoring. A cooperative partnership among all stakeholders and research communities is another key element for success, which facilitates the integration of multidisciplinary expertise, mobilizing considerable resources and support. The measurement and assessment results provided an overall picture about how far Deqing County is from the 2030 SDGs, and enables the local government to formulate a five-year action plan to address the identified gaps and challenges with tangible actions and allocated resources.

The results of this project were presented and showcased at the first United Nations World Geospatial Information Congress, held from 19-21 November 2018 [37]. It was considered as a "Best practice for implementing and measuring SDGs at the local level" and received positive comments from the international community. The United Nations Expert Committee on Global Geoinformation Management (UN-GGIM) decided at the end of 2018 to "showcase the work as a flagship example on how countries can practically measure their progress using statistical and geospatial information, especially at the sub-national level". In 2019, it was selected by the United Nations as one of the "Best practices in SDGs implementation".

Author Contributions: All of the authors designed the study and discussed the basic structure of the manuscript. Jun Chen, Shu Peng, Hao Chen, Xuesheng Zhao and Yuejing Ge carried out the experiments and analyzed the data; Jun Chen finished the manuscript; Zhilin Li proposed suggestions to improve the quality of the paper. All authors have read and agreed to the published version of the manuscript.

Funding: This research was funded by National Natural Science Foundation of China (No. 41930650) and Chinese Knowledge Center for Engineering Science and Technology (No.CKCEST-2018-2-1).

Acknowledgments: This work has received strong supports from Deqing County Government, the United Nations Economic and Social Council, the Ministry of Natural Resources, the National Bureau of Statistics, Zhejiang Bureau of Statistics, Department of Natural Resources of Zhejiang Province. The authors would also like to thank all the team members who have contributed to this research and practice. 
Conflicts of Interest: The authors declare no conflict of interest.

\section{References}

1. United Nations. Transforming Our World: The 2030 Agenda for Sustainable Development; A/RES/70/1; United Nations: New York, NY, USA, 2015.

2. Schmidt-Traub, G.; De la Mothe Karoubi, E.; Espey, J. Indicators and a Monitoring Framework for the Sustainable Development Goals: Launching a Data Revolution for the SDGs; Sustainable Development Solutions Network: New York, NY, USA, 2015.

3. Maurice, J. Measuring progress towards the SDGs-A new vital science. Lancet 2016, 388, 1455-1458. [CrossRef]

4. UN-GGIM. The Integrated Geospatial Information Framework (IGIF). Available online: https://ggim.un.org/ IGIF/ (accessed on 11 August 2020).

5. UN IAEG-SDGs. Report of the Inter-Agency and Expert Group on Sustainable Development Goal Indicators; E/CN.3/2016/2/Rev.1; United Nations Economic and Social Council: New York, NY, USA, 2016.

6. Persson, Å.; Weitz, N.; Nilsson, M. Follow-up and review of the Sustainable Development Goals: Alignment vs. internalization. Rev. Eur. Comp. Int. Environ. Law 2016, 25, 59-68. [CrossRef]

7. Dizdaroglu, D. The role of indicator-based sustainability assessment in policy and the decision-making process: A review and outlook. Sustainability 2017, 9, 1018. [CrossRef]

8. Scott, G.; Rajabifard, A. Sustainable development and geospatial information: A strategic framework for integrating a global policy agenda into national geospatial capabilities. Geo-Spat. Inf. Sci. 2017, 20, 59-76. [CrossRef]

9. Liverman, D.M. Geographic perspectives on development goals: Constructive engagements and critical perspectives on the MDGs and the SDGs. Dialogues Hum. Geogr. 2018, 8, 168-185. [CrossRef]

10. Schmidt-Traub, G.; Kroll, C.; Teksoz, K.; Durand-Delacre, D.; Sachs, J.D. National baselines for the Sustainable Development Goals assessed in the SDG Index and Dashboards. Nat. Geosci. 2017, 10, 547-555. [CrossRef]

11. SDSN. Data, Indicators, and Follow-Up \& Review [EB/OL]. Available online: http://unsdsn.org/what-we-do/ data-indicators-follow-up-review/ (accessed on 6 February 2018).

12. Allen, C.; Nejdawi, R.; El-Baba, J.; Hamati, K.; Metternicht, G.; Wiedmann, T. Indicator-based assessments of progress towards the sustainable development goals (SDGs): A case study from the Arab region. Sustain. Sci. 2017, 12, 975-989. [CrossRef]

13. Nhemachena, C.; Matchaya, G.; Nhemachena, C.R.; Karuaihe, S.; Muchara, B.; Nhlengethwa, S. Measuring baseline agriculture-related sustainable development goals index for southern Africa. Sustainability 2018, 10, 849. [CrossRef]

14. Allen, C.; Reid, M.; Thwaites, J.; Glover, R.; Kestin, T. Assessing national progress and priorities for the Sustainable Development Goals (SDGs): Experience from Australia. Sustain. Sci. 2020, 15, 521-538. [CrossRef]

15. Xu, Z.; Chau, S.N.; Chen, X.; Zhang, J.; Li, Y.; Dietz, T.; Wang, J.; Winkler, J.A.; Fan, F.; Huang, B. Assessing progress towards sustainable development over space and time. Nature 2020, 577, 74-78. [CrossRef]

16. Nagy, J.A.; Benedek, J.; Ivan, K. Measuring sustainable development goals at a local level: A case of a metropolitan area in Romania. Sustainability 2018, 10, 3962. [CrossRef]

17. Estoque, R.C. A Review of the Sustainability Concept and the State of SDG Monitoring Using Remote Sensing. Remote Sens. 2020, 12, 1770. [CrossRef]

18. Stokes, E.C.; Seto, K.C. Characterizing urban infrastructural transitions for the Sustainable Development Goals using multi-temporal land, population, and nighttime light data. Remote Sens. Environ. 2019, 234, 111430-111441. [CrossRef]

19. Ishtiaque, A.; Masrur, A.; Rabby, Y.W.; Jerin, T.; Dewan, A. Remote Sensing-Based Research for Monitoring Progress towards SDG 15 in Bangladesh: A Review. Remote Sens. 2020, 12, 691. [CrossRef]

20. Geng, W.; Chen, J.; Zhang, H.; Xu, K. Task and progress of IAEG-SDGS: WGGI in monitoring SDGs through a'geographic location'lens. Int. Arch. Photogramm. Remote Sens. Spat. Inf. Sci. 2018, 42, 385-390. [CrossRef] 
21. UNGGIM. Inter-Agency and Expert Group on the Sustainable Development Goal Indicators (IAEG-SDGS) Working Group on Geospatial Information. Available online: http://ggim.un.org/UNGGIM-wg6/ (accessed on 11 August 2020).

22. UN-GGIM. The Global Statistical Geospatial Framework. Available online: http://ggim.un.org/meetings/ GGIM-committee/9th-Session/documents/The_GSGF.pdf (accessed on 11 August 2020).

23. Anderson, K.; Ryan, B.; Sonntag, W.; Kavvada, A.; Friedl, L. Earth observation in service of the 2030 Agenda for Sustainable Development. Geo-Spat. Inf. Sci. 2017, 20, 77-96. [CrossRef]

24. Chinese Academy of Sciences. Earth Big Data Supporting Sustainable Development Goals. Available online: http://www.aircas.cas.cn/dtxw/rdxw/201909/t20190927_5402026.html (accessed on 31 September 2019).

25. Andries, A.; Morse, S.; Murphy, R.; Lynch, J.; Woolliams, E.; Fonweban, J. Translation of Earth observation data into sustainable development indicators: An analytical framework. Sustain. Dev. 2019, 27, 366-376. [CrossRef]

26. Andries, A.; Morse, S.; Murphy, R.J.; Lynch, J.; Woolliams, E.R. Seeing sustainability from space: Using Earth observation data to populate the UN Sustainable Development Goal indicators. Sustainability 2019, 11, 5062. [CrossRef]

27. Masó, J.; Serral, I.; Domingo-Marimon, C.; Zabala, A. Earth observations for sustainable development goals monitoring based on essential variables and driver-pressure-state-impact-response indicators. Int. J. Digit. Earth 2020, 13, 217-235. [CrossRef]

28. Kuffer, M.; Wang, J.; Nagenborg, M.; Pfeffer, K.; Kohli, D.; Sliuzas, R.; Persello, C. The scope of earth-observation to improve the consistency of the SDG slum indicator. ISPRS Int. J. of Geo-Inf. 2018, 7, 428. [CrossRef]

29. Xiao, W.; Mills, J.; Guidi, G.; Rodríguez-Gonzálvez, P.; Barsanti, S.G.; González-Aguilera, D. Geoinformatics for the conservation and promotion of cultural heritage in support of the UN Sustainable Development Goals. ISPRS J. Photogramm. Remote Sens. 2018, 142, 389-406. [CrossRef]

30. Choi, J.; Hwang, M.; Kim, G.; Seong, J.; Ahn, J. Supporting the measurement of the United Nations' sustainable development goal 11 through the use of national urban information systems and open geospatial technologies: A case study of south Korea. Open Geospat. Data Softw. Stand. 2016, 1, 4-13. [CrossRef]

31. Boyd, D.S.; Jackson, B.; Wardlaw, J.; Foody, G.M.; Marsh, S.; Bales, K. Slavery from space: Demonstrating the role for satellite remote sensing to inform evidence-based action related to UN SDG number 8. ISPRS J. Photogramm. Remote Sens. 2018, 142, 380-388. [CrossRef]

32. Whitcraft, A.K.; Becker-Reshef, I.; Justice, C.O.; Gifford, L.; Kavvada, A.; Jarvis, I. No pixel left behind: Toward integrating Earth Observations for agriculture into the United Nations Sustainable Development Goals framework. Remote Sens. Environ. 2019, 235, 111470-111484. [CrossRef]

33. Kussul, N.; Lavreniuk, M.; Kolotii, A.; Skakun, S.; Rakoid, O.; Shumilo, L. A workflow for sustainable development goals indicators assessment based on high-resolution satellite data. Int. J. Digit. Earth 2019, 13, 309-321. [CrossRef]

34. Nilsson, M.; Griggs, D.; Visbeck, M. Policy: Map the interactions between Sustainable Development Goals. Nature 2016, 534, 320-322. [CrossRef]

35. Lu, Y.; Wang, Y.; Yuan, J.; He, G. Some thoughts on promoting the implementation of sustainable development goals in China. China Popul. Resour. Environ. 2018, 28, 1-9.

36. Chen, J.; Ren, H.; Geng, W.; Peng, S.; Ye, F. Quantitative measurement and monitoring sustainable development goals (SDGs) with geospatial information. Geomat. World 2018, 25, 1-7.

37. Chen, J.; Li, Z. China tracks its progress on SDGs. Nature 2018, 563, 184. [CrossRef]

38. Chen, J.; Peng, S.; Zhao, X.S.; Ge, Y.J.; Li, Z.L. Measuring regional progress towards SDGs by combining geospatial and statistical information. Acta Geod. Cartogr. Sin. 2019, 48, 473-479.

39. Qiu, Y.; Zhao, X.; Fan, D.; Li, S. Geospatial disaggregation of population data in supporting SDG assessments: A case study from Deqing County, China. ISPRS Int. J. Geo-Inf. 2019, 8, 356. [CrossRef]

40. Chen, J.; Zhang, J.; Zhang, W.W.; Peng, S. Continous Updating and Refinement of Land Cover Data Product. J. Remote Sens. 2016, 20, 991-1001.

41. Liu, S.; Bai, J.; Chen, J. Measuring SDG 15 at the County Scale: Localization and Practice of SDGs Indicators Based on Geospatial Information. ISPRS Int. J. of Geo-Inf. 2019, 8, 515. [CrossRef]

42. Deqing Government. Deqing Statistical Yearbook; China Statistical Publishing House: Beijing, China, 2017. 
43. Holt, J.B.; Lo, C.; Hodler, T.W. Dasymetric estimation of population density and areal interpolation of census data. Cartogr. Geogr. Inf. Sci. 2004, 31, 103-121. [CrossRef]

44. Lu, N.; Zhang, W.; Chen, L.; Li, Z.; Chen, J.; Li, R.; Chen, X.; Zhang, Y.; Liu, J. Estimation of large regional urban and rural population density based on the differences of population distribution between urban and rural: Take Shandong Province as example. Acta Geod. Cartogr. Sin. 2015, 44, 1384-1391.

45. Sachs, J.; Schmidt-Traub, G.; Kroll, C.; Durand-Delacre, D.; Teksoz, K. SDG Index and Dashboards Report 2017; Bertelsmann Stiftung and Sustainable Development Solutions Network (SDSN): New York, NY, USA, 2017; Available online: http://sdgindex.org/reports/2017/ (accessed on 16 February 2018).

46. The State Council of the People's Republic of China. China's National Plan on Implementation of the 2030 Agenda for Sustainable Development; The State Council of the People's Republic of China: Beijing, China, 2016. Available online: http://www.gov.cn/xinwen/2016-10/13/content_5118514.htm (accessed on 31 August 2020).

47. United Nations. Step-by-Step Methodology for Monitoring Ecosystems (6.6.1). Available online: https://www.unwater.org/publications/step-step-methodology-monitoring-ecosystems-6-6-1/ (accessed on 16 February 2018).

48. Kleynhans, C.; Louw, M. River Ecoclassification: Manual for Ecostatus Determination (Version 2)—Module A: EcoClassification and EcoStatus Determination; Water Research Commission: Pretoria, South Africa, 2008.

49. Everitt, B. The Cambridge Dictionary of Statistics; Cambridge University Press: Cambridge, UK, 1998.

50. Kanter, D.R.; Schwoob, M.-H.; Baethgen, W.E.; Bervejillo, J.E.; Carriquiry, M.; Dobermann, A.; Ferraro, B.; Lanfranco, B.; Mondelli, M.; Penengo, C. Translating the sustainable development goals into action: A participatory backcasting approach for developing national agricultural transformation pathways. Glob. Food Secur. 2016, 10, 71-79. [CrossRef]

(C) 2020 by the authors. Licensee MDPI, Basel, Switzerland. This article is an open access article distributed under the terms and conditions of the Creative Commons Attribution (CC BY) license (http://creativecommons.org/licenses/by/4.0/). 